\title{
Revision Microvascular Decompression for Trigeminal Neuralgia and Hemifacial Spasm: Factors Associated with Surgical Failure
} \author{
Steven L. Giannotta ${ }^{3}$ \\ ${ }^{1}$ Neurorestoration Center, Keck School of Medicine, University of \\ Southern California, Los Angeles, California, United States \\ 2 Department of Neurosurgery, University of California, San Diego, \\ San Diego, California, United States \\ ${ }^{3}$ Department of Neurological Surgery, Keck School of Medicine, \\ University of Southern California, Los Angeles, California, \\ United Sates
}

Kristine Ravina ${ }^{1}$ Ben A. Strickland ${ }^{1,3}$ Robert C. Rennert ${ }^{2}$ Joshua Bakhsheshian ${ }^{3}$ Jonathan J. Russin ${ }^{1,3}$

J Neurol Surg B 2019;80:31-39.

\begin{abstract}
Address for correspondence Ben A. Strickland, MD, Department of Neurological Surgery, Keck School of Medicine, University of Southern California, Los Angeles, 1200 North State Street, Suite 3300, Los Angeles, CA 90033, United States (e-mail: ben.strickland@med.usc.edu).
\end{abstract}

\begin{abstract}
Keywords

- hemifacial spasm

- microvascular decompression

- neurovascular conflict

- reoperation

- trigeminal neuralgia

Objective To investigate risk factors for symptom recurrence in patients requiring a revision microvascular decompression (MVD) for trigeminal neuralgia (TN) or hemifacial spasm (HFS).

Design Retrospective review of a prospectively maintained database.

Participants Seventeen consecutive patients undergoing revision MVD at our institution between January 1993 and September 2017.

Main Outcome Measures The incidence and causes for revision MVDs were recorded. Response to revision MVD for TN was tracked using the Barrow Neurological Institute (BNI) grading scale. Response to revision MVD for HFS was graded as "no improvement," "some relief," or "complete resolution" of symptoms.

Results Revision MVD rate for the senior author across all MVDs performed in this period was $1.9 \%$ for TN and $9.3 \%$ for HFS. Initial MVD failure was primarily caused by active inflammation and/or scarring and adhesions in 5/17 patients, malposition/ slippage of Teflon in 3/17 patients, and insufficient Teflon in 1/17 patients. Without other factors, a new site of neurovascular conflict was identified in 4/17 patients, while the same site of neurovascular conflict was found in 3/17 patients. No cause could be identified in $1 / 17$ patients. Scarring was found primarily in the TN group and was associated with symptom persistence.

Conclusion Revision MVD for recurrent TN and HFS is an effective procedure offering the prospect of a complete cure. Proper Teflon use is crucial for surgical success. Scarring after initial MVD is a negative prognostic factor requiring destructive treatment consideration. Although morbidity rates were slightly increased with revision versus original MVDs, the complications were non-disabling and resolved over time.
\end{abstract}

received

April 16, 2018

accepted

May 11, 2018

published online

June 29, 2018 (c) 2019 Georg Thieme Verlag KG

Stuttgart · New York
DOI https://doi.org/

10.1055/s-0038-1661348. ISSN $2193-6331$. 


\section{Introduction}

Trigeminal neuralgia (TN) and hemifacial spasm (HFS) are cranial nerve compression syndromes with similar pathogenic mechanisms, but distinct clinical presentations. TN is the most common cranial nerve compression disorder characterized by paroxysmal, stimulus-evoked, episodes of stabbing or electric shock-like pain in one or more trigeminal nerve distributions. ${ }^{1-3} \mathrm{HFS}$, referred to as the "motor equivalent of TN," is an uncommon condition presenting with repetitive, paroxysmal spasms of the facial muscles. Although painless, HFS significantly interferes with daily activities and can cause psychological and social dysfunction. ${ }^{1,4,5}$ These conditions are thought to result from ectopic excitation and ephaptic transmission from a demyelinated nerve root compression site. ${ }^{6-10}$ Nerve compression in classical TN and HFS is almost exclusively caused by a neurovascular conflict at the trigeminal nerve root and facial nerve root exit zone, respectively. ${ }^{2,11}$

Treatment of TN and HFS is challenging. While control of TN symptoms is possible with medications (e.g., carbamazepine, oxcarbazepine, and baclofen), medication failure, toxicity, or symptom adaptation leads to the consideration of invasive treatment options in nearly half of TN patients. ${ }^{1,3-5,12,13}$ Similarly, botulinum toxin injections can offer temporary relief of HFS symptoms, but require multiple treatments per year and are associated with a risk of facial muscle paralysis. ${ }^{4,5}$ Minimally invasive procedures for the treatment of cranial nerve compression disorders have also been described, including glycerol or radiofrequency rhizotomy, balloon microcompression, and stereotactic radiosurgery, ${ }^{1,14,15}$ but rely on nerve root ablation for symptom relief. Microvascular decompression (MVD), or surgical removal of the neurovascular compression site, is the only non-ablative treatment that can provide a complete etiologic cure for HFS and TN. ${ }^{1,16}$ While highly effective, $~ 10 \%$ of patients have persistent or recurrent symptoms after an MVD. 4,5,11,13,15,17 Herein, we review our experience with revision MVD for TN and HFS and investigate the factors that lead to surgical failure and reoperation.

\section{Methods}

\section{Patient Population}

Patient consent was obtained in compliance with institutional guidelines. A retrospective review of an institutional review board (IRB) approved, prospectively maintained database was performed. A total of 17 patients $(n=9 \mathrm{TN}$ and $n=8$ HFS) who underwent a revision MVD at our institution for recurrent or persistent symptoms between January 1993 and September 2017 were identified and included in the study. Records of patient demographics, intraoperative findings, time of symptom relapse, time between surgeries, follow-up time, outcomes, and complications were collected and analyzed. For patients with TN, pain outcomes was evaluated using the Barrow Neurological Institute (BNI) grading scale. ${ }^{18}$ Specifically, BNI grade I (no pain, no medications required) was regarded as complete pain relief, BNI grades I-IIIb were regarded as an adequate pain relief, while treatment failure was defined as BNI grades IV and $\mathrm{V}$ as described by Kano et al. ${ }^{19}$ For patients with HFS, outcomes were graded as "no improvement," "some relief," or "complete resolution" of symptoms.

\section{Surgical Technique}

Revision MVD was offered for recurrent classical TN and HFS patients generally younger than 70 years of age and otherwise healthy. Briefly, the patient is placed in a lateral decubitus position, and the surgical field is prepared and draped for a standard retrosigmoid approach. The previous incision is then reopened and lengthened, if necessary. The previous craniectomy site is identified and enlarged as needed using high-speed diamond tip bur after removing the prior cranioplasty material. Given the typical age group of TN patients being older, the need for cerebrospinal fluid (CSF) evacuation is not as critical; therefore, the craniotomy can be limited and centered closer to the junction of the transverse and sigmoid sinus. However, HFS patients tend to be younger, so the craniotomy is centered closer to the foramen magnum, which is effective in liberating CSF and directing the surgeon to the portion of the vertebral artery (VA)/posterior inferior cerebellar artery (PICA) junction that will be most versatile in affecting decompression. After scar tissue over the dura is gently dissected away, the dura is reopened using the operative microscope. Care is taken to identify and carefully divide adhesions between the dura and cerebellum prior to cerebellar retraction. In our experience, mechanical retraction of the cerebellum is rarely required for achieving an adequate exposure on revision MVDs. The dissection is carried down to the trigeminal cistern. Upon sharp opening of the cistern, branches of the petrosal venous system are coagulated and divided, if necessary. The trigeminal nerve is identified, and its neurovascular relationships are evaluated. In cases of HFS, cranial nerves VII and VIII are identified, and neurovascular relationships at the VII nerve root brain stem exit zone are explored following flocculus retraction. Any potentially offending veins are coagulated and divided. Location of any prior implant material is identified and evaluated. Care is then taken to secure the culprit artery or vein in a new position using Teflon felt with an addition of fibrin glue as necessary. The prior implant material is removed, and adhesions are dissected if any relocation/slippage or inflammation from the material is causing nerve irritation, deviation, or compression. Brainstem auditory evoked response and facial nerve electromyography recordings are monitored throughout the procedure for all patients.

\section{Statistical Analysis}

Continuous variables are reported as median (range). Inverted Kaplan-Meier curves are used to show trends for probability of relapse of TN and HFS and the probability of reoperation over time after initial MVD surgery in both groups. Patients without known time of symptom relapse ( $n=1$ in HFS group) and/or time of initial surgery ( $n=2$ in HFS group) were excluded from these graphs. 


\section{Results}

A total of 17 patients underwent revision MVD at our institution for recurrent TN or HFS during the review period and were included in the study. Eleven (3.8\%) out of a total 286 ( 211 for TN and 75 for HFS) consecutive patients who underwent their initial MVD at our institution required a revision surgery for persistent or recurrent symptoms. The remaining six patients had undergone their initial MVD at an outside hospital. Within our institution, revision MVD rates for recurrent classical TN and HFS were $1.9 \%(n=4 / 211)$ and
$9.3 \%$ ( $n=7 / 75)$, respectively. Among the 11 revisions performed at our institution, six cases were performed by the senior author. A retrosigmoid craniotomy for MVD was the initial and repeated surgical approach for all TN and HFS patients.

\section{Revision Microvascular Decompression for Recurrent Trigeminal Neuralgia}

Nine patients with recurrent classical TN underwent a revision MVD (eight females and one male; median age 66 [3276] years) (-Table 1). Follow-up time after revision MVD

Table 1 Summary of characteristics and clinical outcomes of recurrent trigeminal neuralgia patients undergoing repeated microvascular decompression

\begin{tabular}{|l|l|l|l|l|l|l|l|}
\hline $\begin{array}{l}\text { Case } \\
\text { no. }\end{array}$ & $\begin{array}{l}\text { Age at } \\
\text { revision MVD } \\
\text { (years), sex }\end{array}$ & $\begin{array}{l}\text { Initial } \\
\text { compression } \\
\text { cause }\end{array}$ & $\begin{array}{l}\text { Immediate } \\
\text { response to } \\
\text { initial MVD }\end{array}$ & $\begin{array}{l}\text { Time until } \\
\text { relapse } \\
\text { after initial } \\
\text { MVD } \\
\text { (years) }\end{array}$ & $\begin{array}{l}\text { Time } \\
\text { between } \\
\text { surgeries } \\
\text { (years) }\end{array}$ & Classification & $\begin{array}{l}\text { Repeat } \\
\text { compression } \\
\text { cause }\end{array}$ \\
\hline 1 & $70, \mathrm{M}$ & SCA & No improvement & 0 & 19 & Type 1 & SCA \\
\hline 2 & $66, \mathrm{~F}$ & SCA & No improvement & 0 & 2 & Type 1 & Petrosal veins \\
\hline 3 & $45, \mathrm{~F}$ & AICA & $\begin{array}{l}\text { Complete } \\
\text { resolution }\end{array}$ & 10 & 14 & Type 1 & Teflon granuloma \\
\hline 4 & $66, \mathrm{~F}$ & AICA & $\begin{array}{l}\text { Complete } \\
\text { resolution }\end{array}$ & 17 & 19 & Type 1 & $\begin{array}{l}\text { Petrosal veins, } \\
\text { SCA }\end{array}$ \\
\hline 5 & $62, \mathrm{~F}$ & SCA & No improvement & 0 & $<1$ & Type 2 & Petrosal veins \\
\hline 6 & $73, \mathrm{~F}$ & SCA & Some relief & 3 & 8 & Type 2 & Teflon granuloma \\
\hline 7 & $76, \mathrm{~F}$ & SCA & Some relief & 4 & 6 & Type 2 & $\begin{array}{l}\text { Slipped Teflon } \\
\text { pledget, petrosal } \\
\text { vein }\end{array}$ \\
\hline 8 & $72, \mathrm{~F}$ & SCA & $\begin{array}{l}\text { Complete } \\
\text { resolution }\end{array}$ & 2 & 2 & 1 & Type 1 \\
\hline 9 & $32 . \mathrm{F}$ & SCA & Some relief & 1 & Type 2 & Petrosal vein \\
\hline
\end{tabular}

\begin{tabular}{|c|c|c|c|c|c|c|c|}
\hline $\begin{array}{l}\text { Case } \\
\text { No. }\end{array}$ & $\begin{array}{l}\text { Scarring/ } \\
\text { adhesions } \\
\text { found intra- } \\
\text { operatively }\end{array}$ & $\begin{array}{l}\text { BNI score } \\
\text { prior to } \\
\text { repeat MVD }\end{array}$ & $\begin{array}{l}\text { BNI score after } \\
\text { repeat MVD }\end{array}$ & $\begin{array}{l}\text { Radiosurgery } \\
\text { prior revision } \\
\text { MVD? }\end{array}$ & $\begin{array}{l}\text { Latest } \\
\text { follow-up } \\
\text { time } \\
\text { (months) }\end{array}$ & $\begin{array}{l}\text { Same } \\
\text { surgeon }\end{array}$ & Complications \\
\hline 1 & No & V & I & Yes & 3 & No & None \\
\hline 2 & No & IV & IIIb & No & 4 & No & None \\
\hline 3 & Yes & IV & II & No & 12 & No & $\begin{array}{l}\text { V2-V3 distribu- } \\
\text { tion numbness, } \\
\text { transient CN VI } \\
\text { palsy }\end{array}$ \\
\hline 4 & Yes & $\mathrm{n} / \mathrm{a}^{\mathrm{a}}$ & $n / a^{a}$ & No & 1 & No & None \\
\hline 5 & No & V & Illa & No & 36 & Yes & None \\
\hline 6 & Yes & IV & IIIb & Yes & 24 & No & None \\
\hline 7 & No & $n / a^{b}$ & 1 & Yes & 36 & No & None \\
\hline 8 & No & IV & I & No & $<1$ & No & None \\
\hline 9 & No & V & V & No & 36 & No & None \\
\hline
\end{tabular}

Abbreviations: AICA, anterior inferior cerebellar artery; BNI, Barrow Neurological Institute; CN, cranial nerve; MVD, microvascular decompression; SCA, superior cerebellar artery.

apatient was not tolerating any of the medications due to comorbidities.

${ }^{b}$ No data on pain severity prior to repeat MVD available. 
ranged from 1 week to 36 months. Time until full symptom relapse after the initial MVD surgery was $2(0-17)$ years. After the initial MVD, three patients had complete symptom resolution, three had some relief, and three had no documented improvement. Median time interval between surgeries was 6(0-19) years. At time of presentation for revision MVD, TN symptoms were classified as type 1 in 5/9 (55.6\%) and type 2 in 4/9 (44.4\%) patients. The compressive structure causing the initial neurovascular conflict was the superior cerebellar artery (SCA) in 7/9 patients and the anterior inferior cerebellar artery (AICA) in 2/9 patients. At the time of repeat retrosigmoid craniotomy, petrosal veins were identified as the potential source of nerve compression in 5/9 patients (cases 2 [-Fig. 1], 4 [-Fig. 2], 5, 8, and, in addition to slipped Teflon, 7). Use of Teflon material during the initial surgery was related to unsatisfactory outcomes in $3 / 9(33.3 \%)$ patients. In cases 3 and 6 , nerve compression by a granulomatous inflammation mass containing Teflon material was revealed (-Fig. $\mathbf{3}$ ). In case 7 , a malpositioned Teflon pledget along with adjacent petrosal vein was identified as the sources of trigeminal nerve deviation and compression. In cases 1 (-Fig. 4) and 4 (-Fig. 2), repeated neurovascular conflict was caused by the SCA (in addition to petrosal veins in case 4). No potential source of nerve compression could be identified in case 9.

Three of the TN patients (cases 1, 6, and 7) underwent gamma knife radiosurgery (GKRS) prior to the revision MVD, one of which was found to have an inflammatory reaction with scarring and adhesions (case 6). Following revision surgery, TN outcomes based on the BNI pain scoring system could be assessed in eight out of nine patients. Complete resolution of TN symptoms (BNI grade I) was reported in three $(37.5 \%)$ patients, while occasional pain without need for medications (BNI grade II) was reported in one (12.5\%) patient. Further, one (12.5\%) patient had no pain with continued medications (BNI grade IIIa), two (25\%) had improved pain controlled with medications (BNI grade IIIb), and one (12.5\%) had no pain relief (BNI grade V). Overall, adequate pain relief (BNI grades I-IIIb) was achieved in 7/9 (87.5\%) patients.

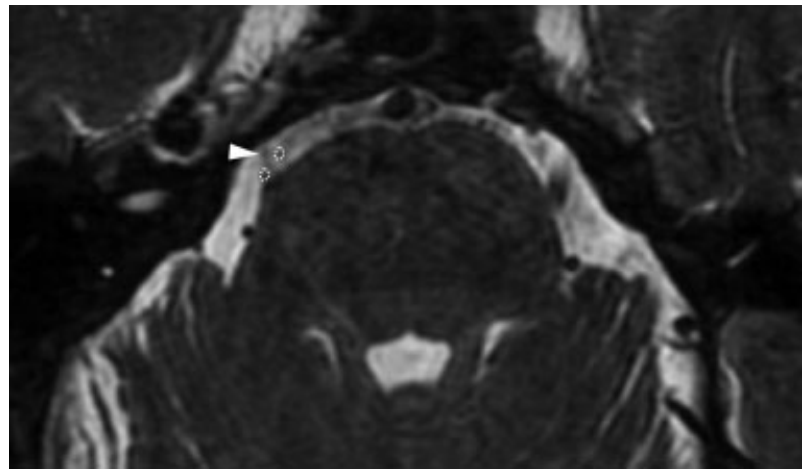

Fig. 2 Recurrent trigeminal neuralgia from new neurovascular sources with scarring formation following initial microvascular decompression. Axial three-dimension FRFSE sequence obtained for symptom recurrence 18 years after the initial microvascular decompression of trigeminal nerve from anterior inferior cerebellar artery, showing an atrophic right trigeminal nerve (arrowhead) and possible compression by a vessel loop (dotted line). Intraoperatively, compression by petrosal vein tributaries and the superior cerebellar artery was found (case 4). FRFSE, fast relaxation fast spin echo.

\section{Revision Microvascular Decompression for Recurrent Hemifacial Spasm}

Eight patients with recurrent HFS underwent a repeat MVD (five females and three males; median age 59 [47-66] years) (-Table 2). Follow-up time after revision MVD ranged from 2 weeks to 3 months. Three patients had no improvement in their symptoms after the initial MVD. For the rest of the patients, time until relapse ranged from 3 days to 4 years. In these patients, three had a complete resolution of HFS symptoms, and two had some relief of their HFS symptoms after their initial MVD before full symptom relapse had occurred. Of the patients reporting complete resolution of symptoms after the initial MVD, two reported a relapse within the first year, while the other continued to be asymptomatic for 4 years. Median time interval between surgeries was $1(0.1-7)$ year. The cause of the initial neurovascular conflict was found to be the PICA in $5 / 8$ patients, the VA in $2 / 8$, and the AICA in $1 / 8$ cases. At the time of repeated

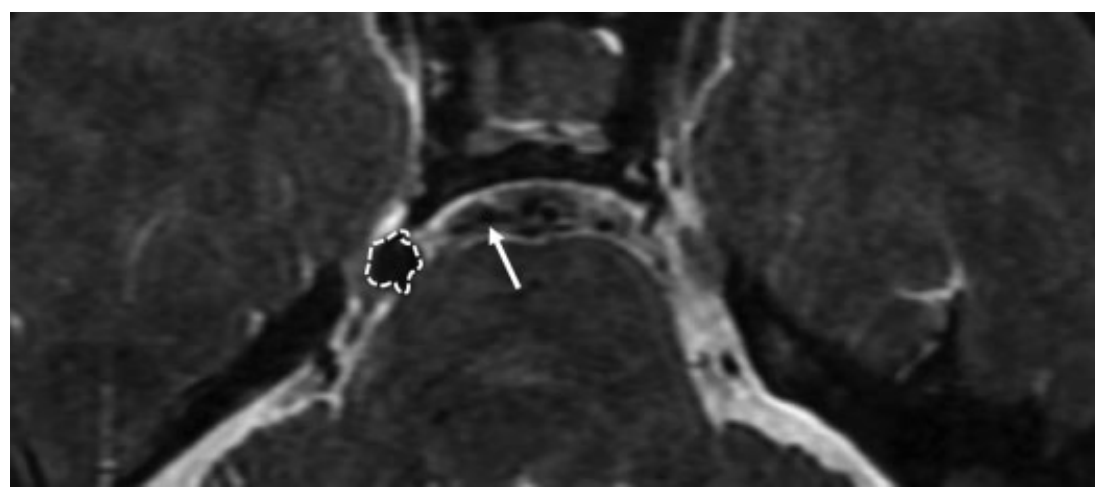

Fig. 1 Recurrent trigeminal neuralgia from venous compression following initial MVD. Axial three-dimension FRFSE magnetic resonance imaging sequence obtained for symptom persistence 2 years after the initial MVD of trigeminal nerve from the SC), showing a hypointense implant mass (dashed line) separating the distal cisternal segment of right trigeminal nerve from the SCA loop (arrow). Repeat MVD was performed due to symptom persistence where a new neurovascular conflict from the petrosal vein was identified (case 2 ). FRFSE, fast relaxation fast spin echo; MVD, microvascular decompression; SCA, superior cerebellar artery. 

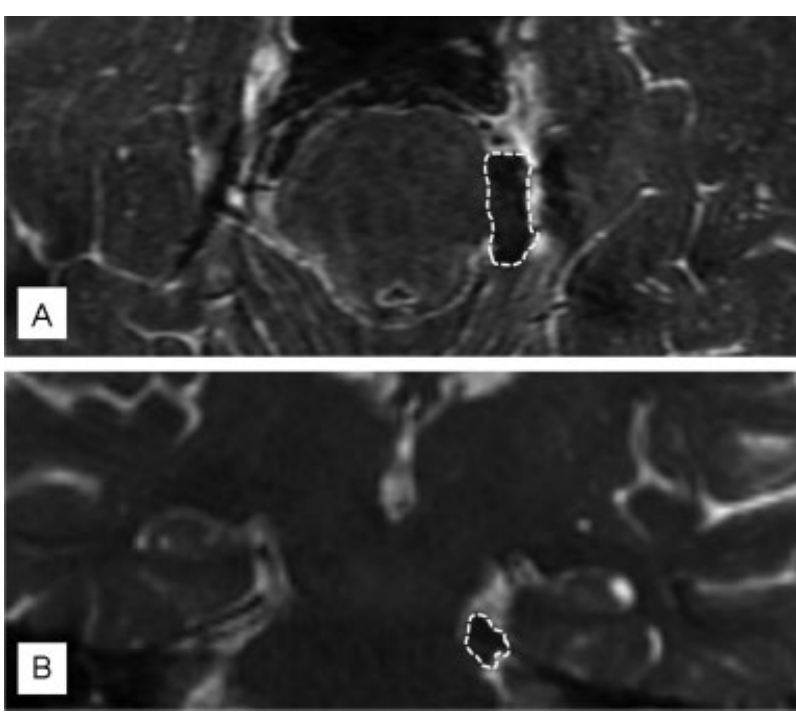

Fig. 3 Recurrent trigeminal neuralgia from a Teflon granuloma following initial microvascular decompression. Axial three-dimension FRFSE $(A)$ and coronal pre-contrast magnetic resonance imaging sequence (B) obtained for symptom persistence/recurrence 8 years after the initial microvascular decompression of trigeminal nerve from the superior cerebellar artery, showing a hypointense mass in the left peripontine cistern (dashed line). Intraoperatively, an inflamed Teflon mass adherent to the trigeminal nerve and causing compression was found (case 6). FRFSE, fast relaxation fast spin echo.

MVD, Teflon use-related surgical failure was identified as the sole or partial cause of repeat symptoms in $5 / 8$ cases. These Teflon-related failures included development of a granuloma (case 10) (-Fig. 5), Teflon-related adhesions (case 13), insufficient amount of Teflon (case 15), and a malpositioned Teflon pledget (cases 12 and 17). Three patients had symptom relapse caused by the same offending vessel addressed by the initial MVD (case 11, 15, and 16; in addition to insufficient Teflon in case 15), while the remaining case developed symptoms due to a new culprit vessel causing nerve compression (case 14).

Complete resolution of HFS symptoms following revision MVD was achieved in all but one patient (case 16), who had residual minor spasms, hypalgesia, and facial numbness that improved at the latest follow-up. In this case, the VA was fixed to the petroclival dura with fibrin glue during the initial surgery to achieve adequate decompression of the facial nerve, though the fibrin complex also encompassed the glossopharyngeal nerve. The surgical failure was a result of remigration of the VA with the glossopharyngeal nerve still tethered in the fibrin complex. Ultimately, the VA could not be dissected from the glossopharyngeal nerve, and Teflon material was used to buttress the entire construct to prevent conflict with the facial nerve.

\section{Combined Causes for Revision Microvascular Decompression}

Initial MVD failure was caused primarily by active inflammation and/or scarring and adhesions in 5/17 patients, malposition/slippage of Teflon material in 3/17 patients, and insufficient Teflon material in $1 / 17$ patients. Without other factors, a new site of neurovascular conflict was identified in $4 / 17$ patients, and the same site of neurovascular conflict was identified in 3/17 patients. No apparent cause could be found in $1 / 17$ of the cases. Complete symptom resolution was achieved in 10/17 patients, and $6 / 17$ patients had symptom improvement after revision MVD. The patient without an obvious identifiable cause for recurrent symptoms on revision surgery had no change in symptoms postoperatively.

Complications were encountered in 4/17 cases following revision MVD. Case 3 developed V2-V3 distribution numbness and transient VI nerve palsy. Case 11 developed a CSF leak with resultant meningitis and eventually required a shunt placement. Case 15 developed a recurring pseudomeningocele, ultimately requiring shunt placement. Case 16 developed meningitis in the postoperative period.

\section{Discussion}

MVD is an established treatment for medically intractable TN and HFS, offering the prospect of permanent cure. Nevertheless, a significant proportion of these patients suffer recurrent symptoms and could benefit from revision MVD. In this series, we retrospectively reviewed cases of revision

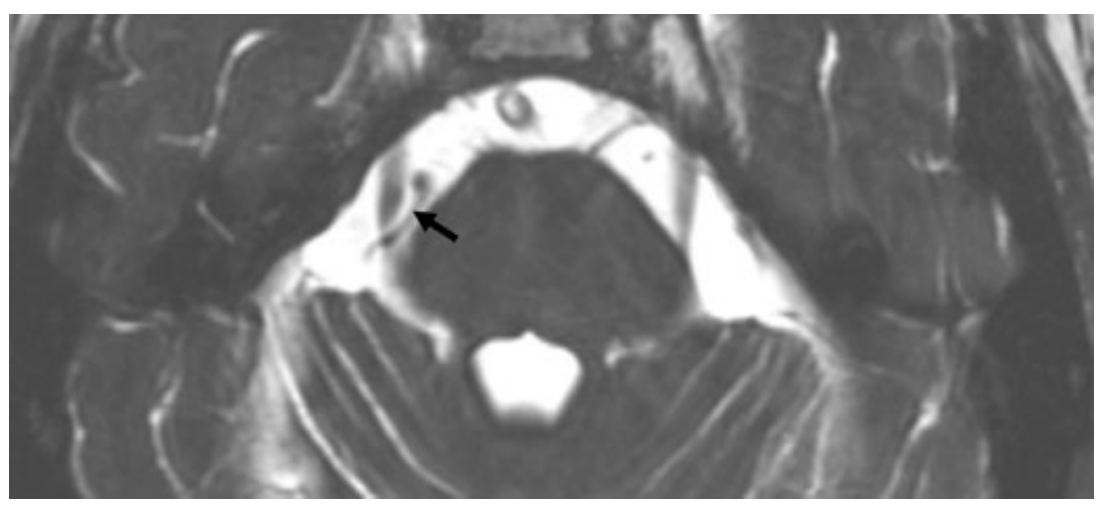

Fig. 4 Recurrent trigeminal neuralgia from the same vascular structure following initial microvascular decompression. Axial FIESTA sequence obtained for symptom persistence 19 years after the initial microvascular decompression of trigeminal nerve from the SCA, demonstrating right trigeminal nerve contact with an SCA loop (arrow). Neurovascular conflict with the SCA was confirmed intraoperatively and treated with Teflon and fibrin glue (case 1). FIESTA, fast imaging employing steady-state acquisition; SCA, superior cerebellar artery. 
Table 2 Summary of characteristics and clinical outcomes of recurrent hemifacial spasm patients undergoing repeated microvascular decompression

\begin{tabular}{|l|l|l|l|l|l|l|}
\hline Case no. & $\begin{array}{l}\text { Age at revision } \\
\text { MVD (years), } \\
\text { Sex }\end{array}$ & $\begin{array}{l}\text { Initial } \\
\text { compression } \\
\text { cause }\end{array}$ & $\begin{array}{l}\text { Immediate } \\
\text { response to } \\
\text { initial MVD }\end{array}$ & $\begin{array}{l}\text { Time until } \\
\text { relapse after } \\
\text { initial MVD } \\
\text { (years) }\end{array}$ & $\begin{array}{l}\text { Time between } \\
\text { surgeries } \\
\text { (years) }\end{array}$ & $\begin{array}{l}\text { Repeat } \\
\text { compression } \\
\text { cause }\end{array}$ \\
\hline 10 & $66, \mathrm{~F}$ & PICA & Some relief & $<1$ & $<1$ & $\begin{array}{l}\text { Teflon } \\
\text { granuloma }\end{array}$ \\
\hline 11 & $62, \mathrm{M}$ & AICA & $\begin{array}{l}\text { Complete } \\
\text { resolution }\end{array}$ & 4 & 7 & AICA \\
\hline 12 & $63, \mathrm{M}$ & VA & $\begin{array}{l}\text { No } \\
\text { improvement }\end{array}$ & 0 & Unknown & $\begin{array}{l}\text { Slipped Teflon } \\
\text { pledget }\end{array}$ \\
\hline 13 & $47, \mathrm{~F}$ & PICA & $\begin{array}{l}\text { No } \\
\text { improvement }\end{array}$ & 0 & 3 & $\begin{array}{l}\text { Teflon adhe- } \\
\text { sions, petrosal } \\
\text { vein }\end{array}$ \\
\hline 14 & $56, \mathrm{~F}$ & PICA & $\begin{array}{l}\text { Complete } \\
\text { resolution }\end{array}$ & $<1$ & 1 & AICA \\
\hline 15 & $66, \mathrm{~F}$ & PICA & $\begin{array}{l}\text { Complete } \\
\text { resolution }\end{array}$ & $<1$ & $<1$ & $\begin{array}{l}\text { PICA, insuffi- } \\
\text { cient Teflon }\end{array}$ \\
\hline 16 & $50, \mathrm{~F}$ & VA & PICA & Some relief & $<1$ & VA \\
\hline
\end{tabular}

\begin{tabular}{|l|l|l|l|l|}
\hline Case No. & $\begin{array}{l}\text { Scarring/adhesions } \\
\text { found intraoperatively }\end{array}$ & $\begin{array}{l}\text { Outcome at follow-up } \\
\text { after revision MVD } \\
\text { (months) }\end{array}$ & Same surgeon & Complications \\
\hline 10 & No & Complete resolution (3) & Yes & None \\
\hline 11 & No & $\begin{array}{l}\text { Complete resolution }(<1) \\
\text { shunt, meningitis }\end{array}$ & No & None \\
\hline 12 & No & $\begin{array}{l}\text { Complete resolution } \\
(<12)\end{array}$ & Yes & None \\
\hline 13 & Yes & Complete resolution (3) & No & None \\
\hline 14 & No & Complete resolution (1) & Yes & $\begin{array}{l}\text { CSF leak requiring LP } \\
\text { shunt }\end{array}$ \\
\hline 15 & No & $\begin{array}{l}\text { Complete resolution (3) } \\
\text { second and third } \\
\text { surgeries, yes }\end{array}$ & Meningitis \\
\hline 16 & No & Improved (3) & $\begin{array}{l}\text { Yes } \\
(<1)\end{array}$ & No \\
\hline
\end{tabular}

Abbreviations: AICA, anterior inferior cerebellar artery; CSF, cerebrospinal fluid; LP, lumboperitoneal; MVD, microvascular decompression; PICA, posterior inferior cerebellar artery; VA, vertebral artery; VP, ventriculoperitoneal.

MVD for recurrent or persistent TN and HFS to investigate potential risk factors for surgical failure. ${ }^{9,15,17}$

In agreement with the literature, $1,5,13,20$ in our series, the SCA and AICA were identified as the most common causes of initial neurovascular conflict in TN, whereas the PICA, VA, and AICA were the most common culprit arteries in HFS. Two of the larger previous case series assessing efficacy of revision MVD for TN report a pain outcome of BNI I in $67 \%$ and $80 \%$ of patients at 1 year, respectively, as compared with $33.3 \%$ in our series. ${ }^{13,15,17}$ Although BNI I outcomes were achieved in only $3 / 9$ cases in our series, we attribute at least some of the discrepancy to the high amount of Type 2 TN patients in our study. Three of the Type 2 patients had BNI scores of IIIa-V, while the fourth achieved BNI I. The reported rates of revision MVD success for HFS range from 73 to $99.9 \%{ }^{8,9,11}$ which are comparable to the $87.5 \%$ success rate in our study.

A comparison between TN and HFS cohorts shows that the TN group had a longer symptom-free period after initial surgery as compared with HFS patients (-Fig. 6). This may stem from a higher percentage of failed HFS cases occurring due to reversible causes (Teflon insufficiency or slippage, insufficient decompression, and possibly incorrect identification of arterial compression source), as opposed to the 


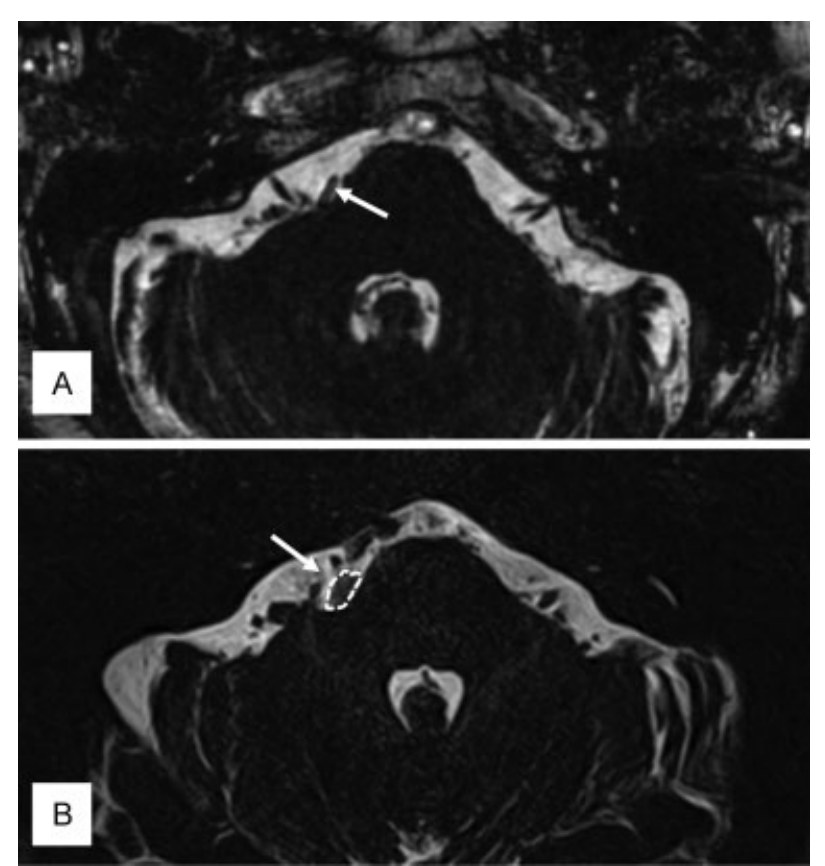

Fig. 5 Recurrent hemifacial spasm from a Teflon granuloma following initial MVD. (A) Axial MRI BASG sequence prior to the initial MVD showing a PICA loop at the right facial nerve root brainstem exit zone causing compression (arrow). (B) Axial three-dimension FASE sequence following the initial MVD showing a Teflon implant (dashed line) separating the PICA (arrow) from the facial nerve root exit zone. Revision MVD was performed for recurrent symptoms, with facial nerve compromise by an inflamed Teflon implant found intraoperatively (case 10). BASG, balanced steady state acquisition rewound gradient echo; FASE, fast asymmetric spin echo; MVD, microvascular decompression; MRI, magnetic resonance imaging; PICA, posterior inferior cerebellar artery.

inflammatory reactions or scarring/adhesions that were more common in TN cases. This also is likely reflective of the benefits of pharmacologic options for symptoms of TN, which can delay presentation for revision surgery and do not exist for symptoms of HFS. Recent studies have emphasized a preference for early revision MVD in HFS since the main cause of persistent or recurrent symptoms is usually an insufficient initial decompression. ${ }^{8,9}$ In line with the literature, we support early revision surgery in HFS to maximize the potential for recurrent symptom relief. However, subsequent experience has caused us to delay revision surgery in HFS for at least 3 months due to the potential for a delayed positive response.

Although somewhat unclear, we identified potential reasons for increased scarring following MVD for TN as compared with HFS. First, in the patients who were found to have scarring or granulomatous change at time of revision, none of the initial MVDs were performed by the senior author at our institution. Specifically, the initial MVD of the four patients with inflammatory changes were all performed at an outside hospital. We surmise potential factors that may attribute to scarring in these particular MVD cases; they include those MVD done by low volume surgeons, saturation of the Tisseel/ pledget construct with blood products at the time of initial MVD, Tisseel contact with the cranial nerve, or as a result of GKRS. As noted by Capelle et al, saturation of the Teflon with blood products at the time of initial MVD is thought to trigger an inflammatory reaction leading to development of Teflon granulomas. ${ }^{21}$ Moreover, following a failed initial MVD, GKRS was performed in three TN patients in this study, one of which showed signs of inflammatory and scarring processes involving the nerve. Adhesion formation has been previously reported in $\sim 20 \%$ of repeated MVD procedures due to failed GKRS and could represent radiation-induced changes. ${ }^{22}$ This observation suggests that GKRS might be a negative prognostic indicator for the success of revision MVD due to scar formation. Additionally, scarring was observed in two TN patients without prior GKRS, both of which did not achieve complete symptom relief after revision MVD. Partial sensory rhizotomy has been recommended if no nerve compression cause can be identified, or there is evidence for an inflammatory process upon repeat MVD. ${ }^{23}$ This procedure, however, may increase postoperative sensory disturbance. In our experience, the presence of scarring on repeat MVD can significantly impact surgical success.

Issues related to the Teflon implant make up a high percentage of revision MVD cases. While widely known for its histocompatibility and resistance to resorption, an increasing number of reports on Teflon implant-related chronic inflammatory reactions and fibrosis are emerging. ${ }^{15,21,24-27}$ Furthermore, correct application of Teflon implant material is crucial for MVD success, as
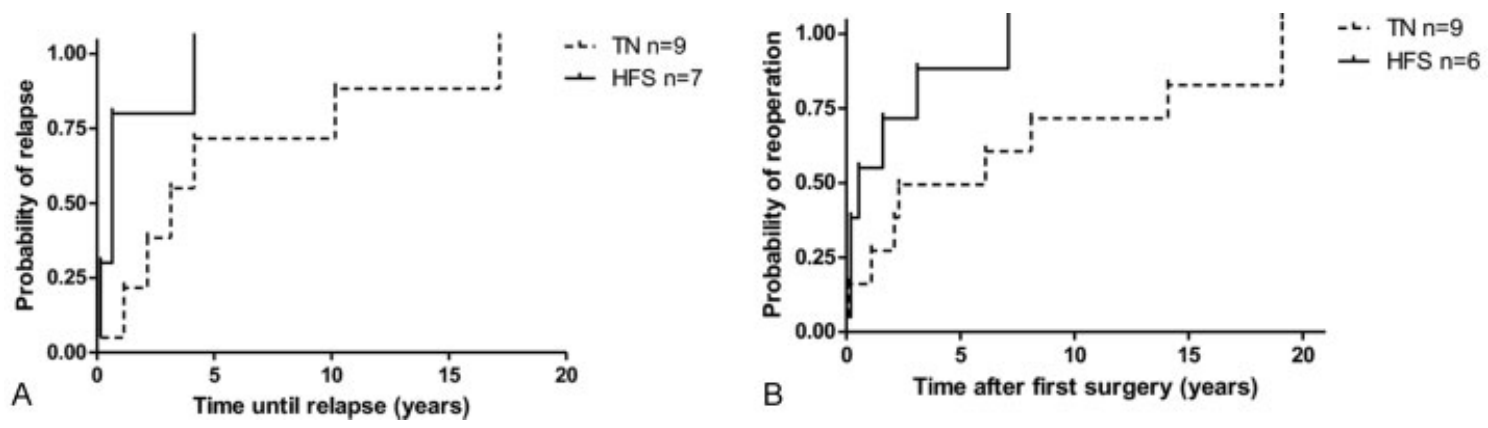

Fig. 6 Kaplan-Meier symptom relapse and reoperation curves. Inverted Kaplan-Meier curves showing the probability of (A) relapse and (B) reoperation following initial microvascular decompression for TN and HFS. HFS, hemifacial spasm; TN, trigeminal neuralgia. 
malpositioned or undersized implants may cause recurrence or exacerbation of neurovascular conflict. ${ }^{15,24}$ In one series, Dou et al reviewed MVD procedures performed during a 9year period and found an MVD failure rate of $6.8 \%$. A total of $81.6 \%$ of the failed cases required revision MVD procedure, of which $74.2 \%$ were due to Teflon implant placement, shape, or size factors. ${ }^{24}$ In our series, a displaced/slipped Teflon pledget was identified as a stand-alone cause of recurrent neurovascular conflict in two HFS patients (cases 12 and 17 ), while it was a co-factor in association with a compressive petrosal vein in one TN patient (case 7). In our practice, these cases reflect a historical surgeon reluctance to use fibrin glue near cranial nerves. As evidence on the safety of fibrin glue application showing no gliotic, fibrotic or neuroinflammatory potential emerged in the early 2000s, its use in neurosurgery became more liberal. ${ }^{28}$ Our practice shows no displacement of implants as a possible cause of surgical failure since 2006, due to careful fibrin glue application to secure the location of Teflon implant. However, it is our practice to avoid allowing the Tisseel glue to come in contact with the nerve being compressed whenever possible. When malpositioned Teflon material was encountered during revision MVD, as much of the material as possible was safely removed, and a new implant material was applied and secured in place using fibrin glue based on surgeon discretion.

In our series, complications developed in 4/17 revision MVD procedures for TN and HFS. The majority of complications were observed in revision MVDs for the HFS group in the form of meningitis and CSF leak. Surprisingly, only $1 / 9$ patients developed sensory complications (case 3) from revision MVD from the TN group (transient V2-V3 distribution numbness). This rate of sensory disturbances is relatively low in comparison to other reports ${ }^{15,17}$ and likely reflects our institutional reluctance for performing more destructive approaches while encountering scarring/adhesions. Although the rate of infectious complications and CSF leak was relatively high in the HFS group, two of these patients achieved a complete cure, while one reported improvement in the clinical symptoms upon follow-up. Admittedly, there is a finite complication rate to revision surgery; however, in this series, the complications were nondisabling, and all patients recovered completely with appropriate management.

Limitations of this study include those inherent to its retrospective, observational study design. Additionally, the small sample size does not allow statistical comparison of outcomes between TN and HFS cases or between initial surgical failure and success groups. Finally, there is a variability in follow-up period for individual patients limiting the ability to draw distinct conclusions about early and late outcomes following initial and revision MVD. Nevertheless, this study reflecting our institutional experience on revision MVDs for TN and HFS over 24 years covers one of the longest timeframes to date and allows for insights into the effects of surgical practice advancement over time.

Ultimately, our institutional experience suggests that the success of revision MVD is greatest when performed by a high-volume surgeon. Other clinical pearls include the critical need to minimize blood products on the Teflon and to avoid contact of Tisseel glue on the cranial nerves at the time of revision surgery. Finally, prior to GKRS for recurrent symptoms, sophisticated imaging should be obtained to rule out recurrent arterial compression as GKRS will complicate any further future attempts of revision MVD.

\section{Conclusion}

The most common causes of initial MVD failures were Teflon related (improper use or inflammatory reactions), followed by a potentially misidentified compression cause and/or insufficient decompression. Although the morbidity profile for repeated MVD is higher than historical reports for initial surgeries, the complications encountered were not life threatening and resolved without disabling sequela. If scarring is identified preoperatively, a more destructive procedure, such as partial rhizotomy, should be considered due to a higher failure risk in case of repeat MVD.

\section{Conflict of Interest}

None.

\section{References}

1 Quinones-Hinojosa A. Schmidek \& Sweet Operative Neurosurgical Techniques: Indications, Methods, and Results. 6th ed. Philadelphia: Saunders; 2012

2 Cruccu G, Finnerup NB, Jensen TS, et al. Trigeminal neuralgia: new classification and diagnostic grading for practice and research. Neurology 2016;87(02):220-228

3 Cruccu G, Gronseth G, Alksne J, et al; American Academy of Neurology Society; European Federation of Neurological Society. AAN-EFNS guidelines on trigeminal neuralgia management. Eur J Neurol 2008;15(10):1013-1028

4 Miller LE, Miller VM. Safety and effectiveness of microvascular decompression for treatment of hemifacial spasm: a systematic review. Br J Neurosurg 2012;26(04):438-444

5 Barker FG II, Jannetta PJ, Bissonette DJ, Shields PT, Larkins MV, Jho HD. Microvascular decompression for hemifacial spasm. J Neurosurg 1995;82(02):201-210

6 Nielsen VK. Pathophysiology of hemifacial spasm: I. Ephaptic transmission and ectopic excitation. Neurology 1984;34(04):418-426

7 Nurmikko TJ, Eldridge PR. Trigeminal neuralgia-pathophysiology, diagnosis and current treatment. Br J Anaesth 2001;87(01):117-132

8 Liu M, Xia L, Zhong J, Li B, Dou N, Li S. What should we do for those hemifacial spasm patients without efficacy following microvascular decompression: expectation of delayed relief or early reoperation? World Neurosurg 2018;110:897-900

9 Zhong J, Xia L, Dou NN, et al. Delayed relief of hemifacial spasm after microvascular decompression: can it be avoided? Acta Neurochir (Wien) 2015;157(01):93-98, discussion 98-99

10 Shin HS, Lee SH, Ko HC, Koh JS. Evaluating transient hemifacial spasm that reappears after microvascular decompression specifically focusing on the real culprit location of vascular compression. World Neurosurg 2017;98:774-779

11 Bigder MG, Kaufmann AM. Failed microvascular decompression surgery for hemifacial spasm due to persistent neurovascular compression: an analysis of reoperations. J Neurosurg 2016;124(01): 90-95

12 Taylor JC, Brauer S, Espir ML. Long-term treatment of trigeminal neuralgia with carbamazepine. Postgrad Med J 1981;57(663): $16-18$ 
13 Barker FG II, Jannetta PJ, Bissonette DJ, Larkins MV, Jho HD. The long-term outcome of microvascular decompression for trigeminal neuralgia. N Engl J Med 1996;334(17):1077-1083

14 Tatli M, Satici O, Kanpolat Y, Sindou M. Various surgical modalities for trigeminal neuralgia: literature study of respective long-term outcomes. Acta Neurochir (Wien) 2008;150(03):243-255

15 Amador N, Pollock BE. Repeat posterior fossa exploration for patients with persistent or recurrent idiopathic trigeminal neuralgia. J Neurosurg 2008;108(05):916-920

16 Kalkanis SN, Eskandar EN, Carter BS, Barker FG II. Microvascular decompression surgery in the United States, 1996 to 2000: mortality rates, morbidity rates, and the effects of hospital and surgeon volumes. Neurosurgery 2003;52(06):1251-1261, discussion 1261-1262

17 Bakker NA, Van Dijk JM, Immenga S, Wagemakers M, Metzemaekers JD. Repeat microvascular decompression for recurrent idiopathic trigeminal neuralgia. J Neurosurg 2014;121(04):936-939

18 Rogers CL, Shetter AG, Fiedler JA, Smith KA, Han PP, Speiser BL. Gamma knife radiosurgery for trigeminal neuralgia: the initial experience of the Barrow Neurological Institute. Int J Radiat Oncol Biol Phys 2000;47(04):1013-1019

19 Kano H, Kondziolka D, Yang HC, et al. Outcome predictors after gamma knife radiosurgery for recurrent trigeminal neuralgia. Neurosurgery 2010;67(06):1637-1644, discussion 1644-1645

20 Li ST, Pan Q, Liu N, Shen F, Liu Z, Guan Y. Trigeminal neuralgia: what are the important factors for good operative outcomes with microvascular decompression. Surg Neurol 2004;62(05):400-404, discussion 404-405
21 Capelle HH, Brandis A, Tschan CA, Krauss JK. Treatment of recurrent trigeminal neuralgia due to Teflon granuloma. J Headache Pain 2010;11(04):339-344

22 Cheng J, Liu W, Hui X, Lei D, Zhang H. Microvascular decompression for trigeminal neuralgia in patients with failed gamma knife surgery: analysis of efficacy and safety. Clin Neurol Neurosurg 2017;161:88-92

23 Kang IH, Park BJ, Park CK, Malla HP, Lee SH, Rhee BA. A clinical analysis of secondary surgery in trigeminal neuralgia patients who failed prior treatment. J Korean Neurosurg Soc 2016;59(06): 637-642

24 Dou NN, Zhong J, Liu MX, et al. Teflon might be a factor accounting for a failed microvascular decompression in hemifacial spasm: a technical note. Stereotact Funct Neurosurg 2016;94(03):154-158

25 Chen J, Lee S, Lui T, Yeh Y, Chen T, Tzaan W. Teflon granuloma after microvascular decompression for trigeminal neuralgia. Surg Neurol 2000;53(03):281-287

26 Matsushima T, Yamaguchi T, Inoue TK, Matsukado K, Fukui M. Recurrent trigeminal neuralgia after microvascular decompression using an interposing technique. Teflon felt adhesion and the sling retraction technique. Acta Neurochir(Wien) 2000;142(05):557-561

27 Toth G, Rubeiz H, Macdonald RL. Polytetrafluoroethylene-induced granuloma and brainstem cyst after microvascular decompression for trigeminal neuralgia: case report. Neurosurgery 2007;61 (04):E875-E877, discussion E877

28 de Vries J, Menovsky T, van Gulik S, Wesseling P. Histological effects of fibrin glue on nervous tissue: a safety study in rats. Surg Neurol 2002;57(06):415-422, discussion 422 